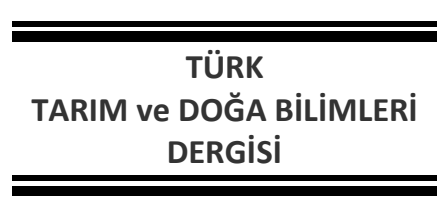

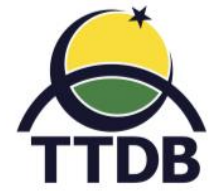

www.dergipark.gov.tr/turkjans

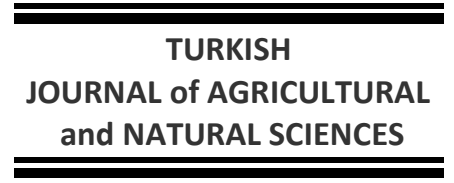

Araştırma Makalesi

\title{
Yağlık Ayçiçeği Genotiplerinin (Helianthus annuus L.) Erzurum Ekolojik Koşullarında Adaptasyonu ve Verim Unsurlarının Belirlenmesi
}

\author{
Fırat SEFAOĞLU*, Canan KAYA
}

Doğu Anadolu Tarımsal Araştırma Enstitüsü Müdürlüğü, Erzurum

*Sorumlu yazar: firat.sefaoglu@tarim.gov.tr

Geliş Tarihi: 14.11.2017

Düzeltme Geliş Tarihi: 24.05.2018

Kabul Tarihi: 26.05.2018

\section{Özet}

Bu araştırmada, bazı yağlık ayçiçeği çeşit (Tunca, Pactol, DKF 2525 ve Tarsan1018) ve hatlarının (ÇNR 129, ÇNR 11-12, ÇNR 12-3, ÇNR 12-13, ÇNR 10-24, ÇNR 12-12) Erzurum ekolojisine adaptasyonları ve verim potansiyellerinin belirlenmesi amaçlanmıştır. Doğu Anadolu Tarımsal Araştırma Enstitüsü Pasinler lokasyonunda 2013 ve 2014 yıllarında tesadüf blokları deneme desenine göre, 4 tekrarlamalı olarak yürütülmüştür. Araştırmada, tabla çapı (cm), bitki boyu $(\mathrm{cm})$, bin tane ağırlığı $(\mathrm{g})$, tane verimi $\left(\mathrm{kg} \mathrm{da}^{-1}\right)$, yağ oranı (\%) ve yağ verimi $\left(\mathrm{kg} \mathrm{da}^{-1}\right)$ gibi parametreler incelenmiştir. İncelenen bütün parametreler bakımından çeşit ve hatlar arasında önemli farklılıkların bulunduğu belirlenmiştir. Çeşit ve hatların verim ve tarımsal özellikleri birlikte değerlendirildiğinde ÇNR 11-12 ve ÇNR 12-12 nolu hatlarının Erzurum ekolojik koşullarına diğer hat ve çeşitler kadar uygun olmadığı saptanmıştır. Sonuç olarak, incelenen birçok özellik yönünden üstün olan ÇNR 10-24 ve ÇNR 12-9 hatlar ile çalışmalara devam edilmesinin uygun olacağına karar verilmiştir.

Anahtar kelimeler: Yağlık ayçiçeği, Helianthus annuus, tabla çapı, tane verimi, yağ oranı.

\section{The Adaptation and Yield Components of Oil Sunflower (Helianthus annuus L.) Genotypes under Erzurum Ecological Conditions}

\begin{abstract}
This study was conducted in order to determine the adaptation and yield potential of some sunflower cultivars (Tunca, Pactol, DKF 2525 ve Tarsan1018) and lines (ÇNR 12-9, ÇNR 11-12, ÇNR 12-3, ÇNR 12-13, ÇNR 1024, ÇNR 12-12) under Erzurum ecological conditions. The experiment was arranged in randomized block design with four replicates in 2013 and 2014 growing seasons on the experimental field of East Agricultural Research Instutu, Pasinler. In the study, genotypes table diameter, plant height, 1000- seed weight, seed yield, crude oil ratio and crude oil yield were investigated. All parameters investigated sowed significant differences among cultivars and lines considered. It was determined ÇNR 11-12 and ÇNR 12-12 were not as suitable as the other cultivars and lines for Erzurum ecological conditions. As a result, it was decided that further studies will be conducted ÇNR 10-24 and ÇNR 12-9, which are superior in terms of many features examined.
\end{abstract}

Key words: Sunflower oil, Helianthus annuus, head diameter, seed yield, oil ratio.

\section{Giriş}

Dünyada yağlı tohumlu bitkileri denildiğinde, soya fasulyesi, yerfıstığı, ayçiçeği, kanola (kolza), mısır, zeytin, susam, palmiye tohumu, yağ keteni, aspir, hindistan cevizi ve hintyağı bitkileri akla gelmektedir. En fazla üretimi yapılan yağlı tohumlu bitkiler soya fasulyesi, kanola, pamuk tohumu, yer fıstığı, ayçiçeği ve palm çekirdeğidir. 2016 yılı verilerine bakıldığında Dünyada 26.63 milyon ha ekim alanı olan yağlık ayçiçeği bitkisinin üretiminin 47.49 milyon ton olduğu görülmektedir. Ülkemizde ayçiçeği, çiğit, soya, yerfıstığı, haşhaş, susam, kolza ve aspir tarımı yapılan yağlı tohumlu bitkilerdir. Bu 
bitkiler içerisinde pamuk yağ bitkisi olmayıp, ülke ekonomisine sağlamış olduğu katma değer bakımından yağ bitkileri arasında kendine yer bulmuştur. Son zamanlarda Ülkemizde yağ bitkileri ekim alanındaki artışa paralel olarak bitkisel yağ tüketimi de artış göstermekte ve bu bağlamda bitkisel yağ üretimine hammadde sağlayacak yağlı tohumlu bitkilerin üretim alanlarını artırabilmek ve yaygınlaştırabilmek için etkili çalışmalar yoğun bir şekilde yapılmaya devam etmektedir. Dünyada ve Ülkemizde en önemli yağ bitkilerinden biri olan ayçiçeği, ülkemizde de en fazla ekim alanına ve üretim miktarına sahip bir yağ bitkisidir. Ülkemizde intiyaç duyulan bitkisel yağ üretiminin \%46'sı ayçiçeğinden karşılanmakla birlikte halkın büyük bir çoğunluğu bitkisel yağ olarak ayçiçeğini tercih etmelerinin sebeplerini yemeklik yağ kalitesinin yüksek, renksiz ve kokusuz oluşu, depolama ve kızartma esnasında oksitadif değişimlere karşı az hassas oluşu gibi nedenlerle sıralayabiliriz. Ülkemizde yıllara göre değişmekle birlikte 6.167.800 hektarda ayçiçeği üretimi yapılmaktadır. Üretimin diğer yağ bitkilerine oranla bu derce yüksek olmasının temel nedenleri ise Trakya Bölgesinde ekim nöbetinde temel bitki oluşu (Buğday-Ayçiçeği), adaptasyon kabiliyetinin geniş ve mekanizasyona oldukça uygun olması, fotoperyoda duyarsız (Goyne ve Hummer 1982), kurağa, soğuğa toleranslı olması, bütün toprak tiplerinde iyi yetişmesi ve farklı ekolojilere adapte olabilmesidir (Carter, 1978). Hemen hemen bütün bölgelerde ayçiçeği yetiştiriciliği yapılmakla birlikte en fazla $(\% 47,2)$ Trakya -Marmara bölgesinde üretilmekte olup, bunu \%29.2 ile Orta Anadolu, \%12 ile Karadeniz \%8.7 ile Akdeniz ve \%2.8 ile Doğu ve Güneydoğu Bölgesi takip etmektedir (Anonim, 2015).

Ülkemizde tüketimi yapılan yağın \%90'ı bitkisel $\% 10^{\prime} u$ ise hayvansal yağlardan karşılanmaktadır. $A B$ ülkelerinde kişi başına yıllık yağ tüketimi $24 \mathrm{~kg}$ civarında iken ülkemizde kişi başına yıllık toplam yağ tüketimi konusunda farklı kaynaklarda farklı veriler bulunmakla birlikte, bu değerin kişi başına $18 \mathrm{~kg} / \mathrm{yıl}$ olarak alınması daha doğru olacaktır (Ekin, 2005). Elde edilen veriler, tüketimimizi karşılayabilmek için yıllık yağ üretimimizin yaklaşık üç milyon ton civarında olması gerektiğini belirtmektedir. Dolayısıyla ülkemizin yağ intiyacının kendine yeterlilik oranı \%25 civarında olup, yıllık yaklaşık 2.2 milyon ton yağ açığımız bulunmaktadır (Anonim, 2016). Bu açığın kapatılmasında, ekim alanlarının artırılması ve birim alandan elde edilen veriminin yükseltilmesi önem arz etmektedir. Bölgenin/yörenin ekolojik koşullarına uyum sağlayabilen yüksek verimli çeşitlerin belirlenmesi veya bu kapsamda geliştirilmesi ekim alanlarının ve birim alan veriminin artırılmasında büyük önem taşımaktadır.

Konu ile ilgili yürütülen bazı çalışmalarda yağlık ayçiçeği verim ve verim öğeleri üzerine ekolojik faktörlerin ve kültürel uygulamaların önemli etkide bulunduğu bildirilmiştir. (Tozlu ve ark. 2008; Sefaoğlu ve ark 2009; Gül 2014; Karakuş ve ark 2014). Daha önce yöremiz koşullarında yürütülen araştırmalarda, tane verimlerinin 251.8$382.5 \mathrm{~kg} \mathrm{da}^{-1}$ yağ verimlerinin $112.6-153.6 \mathrm{~kg} \mathrm{da}^{-1}$, yağ oranlarının ise \%38.1-45.1 arasında değiştiği belirlenmiştir (Albayrak 2014; Gül 2014).

Araştırmanın yürütüldüğü Erzurum ekolojisinde hâkim olan karasal iklim bitkisel çeşitliliği ve verimi kısıtlayan faktörlerden en önemlisidir. Kış mevsiminin soğuk ve uzun olması, ilkbahardaki donların geç, sonbahardaki donların ise erken olması vejetasyon periyodunu kısaltarak bitkinin olgunlaşmasını geciktirmekte ve dolayısı ile verimi önemli ölçüde düşürmektedir. Bu çevresel faktörleri kontrol altına alma olanağımız olmadığı için yeni geliştirilen çeşitlerin üretileceği bölgenin ekolojik koşullarına adapte olması gereklidir. Bir başka ifade ile geliştirilen çeşitlerde yetiştirme tekniği ve ekolojik koşulların bir arada düşünülmesi zorunluluğu vardır (Kurt, 2002). Dolayısıyla bölgemizin ekolojik koşullarına adapte olabilen, verimi yüksek çeşitlerin belirlenmesi ve geliştirilmesine ihtiyaç duyulmaktadır. Bu amaca yönelik olarak Erzurum ekolojik koşullarında yürütülen bu çalışmada, bazı yağlık ayçiçeği çeşit ve hatlarının adaptasyon kabiliyeti ve bazı tarımsal özellikleri incelenmiş bölgemizde daha yüksek performans gösterecek çeşit ve hatların belirlenmesi amaçlanmıştır.

\section{Materyal ve Yöntem \\ Materyal}

Araştırma, TTAE (Trakya Tarımsal Araştırma Enstitüsü) tarafından ve geliştirilen ve ön verim denemelerinden seçilmiş olan altı adet çeşit adayı (ÇNR 12-9, ÇNR 11-12, ÇNR 12-3, ÇNR 12-13, ÇNR 10-24, ÇNR 12-12) ve dört adet kontrol çeşitle (Tunca, Pactol, Tarsan1018 ve DKF 2525) 2013 ve 2014 ürün yıllarında yapılmıştır.

\section{Araştırma Yerinin Iklim Özellikleri}

Araştırmanın yürütüldüğü 2013 ve 2014 ürün yıllarında düşen yağış miktarı uzun yıllar ortalamasından daha düşük olmuştur. Nisan-Eylül dönemine ait düşen yağış miktarı yıllar arasında önemli derecede farklılık göstermiş, araştırmanın ikinci yılının Nisan-Eylül döneminde kaydedilen yağış miktarı birinci yıldan $70 \mathrm{~mm}$ daha fazla olmuştur. Çizelge 1'in incelenmesinden anlaşılacağı üzere Yetişme süresi Nisan-Eylül ayları arasında ortalama sıcaklık bakımından birinci yıl $\left(14.4{ }^{\circ} \mathrm{C}\right)$, 
ikinci yıl $\left(14.9{ }^{\circ} \mathrm{C}\right)$ ve uzun yıllar $\left(13.8{ }^{\circ} \mathrm{C}\right)$ arasındaki fark çok belirgin olmamıştır. Gelişme mevsiminde kaydedilen ortalama sıcaklık ikinci yıl daha fazla olmak üzere her iki ürün yılında uzun yıllar ortalamasından yüksek olmuştur (Çizelge 1).

\section{Araştırma Yerinin Toprak Özellikleri}

Her iki ürün yılında deneme alanı topraklarının killi-tınlı bünyeye sahip olduğu belirlenmiştir. Yapılan analiz sonucunda toprakların organik madde ve gerekse yarayışı fosfor miktarı birinci deneme yılında, ikinci deneme yılından daha yüksektir (Çizelge 2). Yapılan toprak analiz sonucunda elde edile veriler Kacar (2009)'ın vermiş olduğu kriterlerle karşılaştırıldığında; deneme alanı topraklarının bitkilere yarayışlı fosfor ve potasyum yönünden yeterli, hafif alkali, kireç oranı ve organik madde miktarı bakımından ise fakir bir toprak özelliğine sahiptir.

\section{Yöntem}

Araştırma 2013 ve 2014 ürün yıllarında, Doğu Anadolu Tarımsal Araştırma Enstitüsü Pasinler deneme istasyonunda tesadüf blokları deneme desenine göre, 4 tekrarlamalı ve sıra arası $70 \mathrm{~cm}$, sıra üzeri $30 \mathrm{~cm}$ olacak şekilde kurulmuştur. Deneme yılında gübrelerin aktif miktarları hesap edilerek ayrı ayrı tartılıp, 8 kg/da P2O5 gübrenin tamamı, azotlu (\% 21 Amonyum sülfat) gübrenin ise yarısı ( $5 \mathrm{~kg} / \mathrm{da} \mathrm{N}$ ) ekimden hemen önce, azotlu gübrenin kalan yarısı ise Amonyum nitrat formunda bitkiler $15-20 \mathrm{~cm}$ boylandığında uygulanmıştır. Bitkiler toprak yüzeyine çıktıktan 15-21 gün sonra birinci çapa ve her ocakta bir fide kalacak şekilde tekleme yapılmıştır. Yabancı otlarla çapalamayla mücadele edilmiş ve bitkilerin ihtiyaçlarına göre, özellikle çiçeklenme döneminde olmak üzere toplam 3 defa sulama yapılmıştır. Hasat 12 Eylül 2013 ve 22 Eylül 2014 tarihlerinde yapılmıştır. Daha sonra hasat edilen tablalar serada kurutulduktan sonra dövülerek ayçiçeği taneleri çıkarılmış, gerekli sayım ve tartımlar yapılmıştır.

Çizelge 1. Erzurum ilinde denemenin yürütüldüğü yıllara (2013-2014) ve uzun yıllara ortalamalarına ait iklim değerleri ait bazı iklim verileri.

\begin{tabular}{ccccccc}
\hline \multirow{2}{*}{ Aylar } & \multicolumn{3}{c}{ Ortalama Sıcaklık ${ }^{0} \mathrm{C}$} & \multicolumn{3}{c}{ Toplam Yağış (mm) } \\
\cline { 2 - 7 } & 2013 & 2014 & Uzun Yıllar & 2013 & 2014 & Uzun Yıllar \\
\hline Nisan & 7.2 & 7.5 & 5.6 & 36.3 & 31.6 & 58.8 \\
Mayıs & 11.6 & 11.3 & 9.6 & 32.3 & 88.6 & 62.3 \\
Haziran & 15 & 15.3 & 14.6 & 25.1 & 21.6 & 50.2 \\
Temmuz & 19.4 & 20.6 & 19.6 & 7.8 & 27.8 & 26.8 \\
Ağustos & 19.5 & 21.4 & 19.4 & 5.2 & 3.6 & 21.4 \\
Eylül & 13.6 & 13.6 & 13.9 & 11.5 & 11.5 & 16.0 \\
\hline Top & 86.3 & 89.7 & 82.7 & 93.1 & 163.1 & 185.3 \\
\hline Ort. & 14.4 & 14.9 & 13.8 & 15.5 & 27.2 & 30.9 \\
\hline
\end{tabular}

Çizelge 2. Deneme topraklarının bazı fiziksel ve kimyasal özellikleri.

\begin{tabular}{|c|c|c|c|c|c|c|c|c|c|}
\hline 2014 & Erzurum-Pasinler & $\begin{array}{c}\text { Saturasyon } \\
\% \\
60\end{array}$ & $\begin{array}{c}\mathrm{pH} \\
7.41\end{array}$ & $\begin{array}{c}\mathrm{EC} \\
\mathrm{ds} / \mathrm{m} \\
2.32\end{array}$ & $\begin{array}{c}\text { Tuz } \\
\% \\
0.09\end{array}$ & $\begin{array}{c}\text { Kireç } \\
\% \\
2.61\end{array}$ & $\begin{array}{c}\text { Organik } \\
\text { Mad. (\%) } \\
1.29\end{array}$ & $\begin{array}{l}\text { Fosfor } \\
k^{k g ~ d a-1} \\
3.65\end{array}$ & $\begin{array}{c}\text { Potasyum } \\
\mathrm{kg} \mathrm{da}^{-1} \\
181\end{array}$ \\
\hline \multirow[t]{2}{*}{2013} & Erzurum-Pasinler & $\begin{array}{c}\text { Saturasyon } \\
\%\end{array}$ & $\mathrm{pH}$ & $\begin{array}{c}\text { EC } \\
\mathrm{ds} / \mathrm{m}\end{array}$ & $\begin{array}{c}\text { Tuz } \\
\%\end{array}$ & $\begin{array}{c}\text { Kireç } \\
\%\end{array}$ & $\begin{array}{l}\text { Organik } \\
\text { Mad. (\%) }\end{array}$ & $\begin{array}{l}\text { Fosfor } \\
\mathrm{kg} \mathrm{da}^{-1}\end{array}$ & $\begin{array}{c}\text { Potasyum } \\
\mathrm{kg} \mathrm{da}^{-1}\end{array}$ \\
\hline & & 52 & 7.71 & 1.88 & 0.06 & 6.43 & 1.74 & 3.89 & 81 \\
\hline
\end{tabular}

\section{Bulgular ve Tartışma}

Erzurum ekolojik şartlarında 10 yağlık ayçiçeği genotipiyle yapılan çalışmada, incelenen özellikler bakımından ayçiçeği genotipleri arasında önemli farklılıkların olduğunu ve incelenen tüm özelliklerin ortalama değerleri ile bu ortalamaların istatistikî olarak arz ettiği önem $(P<0.05$ veya $\mathrm{P}<0.01$ ) Çizelge $3^{\prime}$, Çizelge 4 ve Çizelge $5^{\prime}$ de verilmiştir. Denemeye alınan ayçiçeği genotiplerinde;

\section{Bitki boyu}

Bitki boyu birinci ürün yılında genotiplerden önemli $\quad(p<0.05) \quad$ derecede etkilenmiştir. Araştırmanın birinci yılında bitki boyu genotiplerin ortalaması olarak $135.0 \mathrm{~cm}$ iken, ikinci ürün yılında az da olsa azalmış ve $132.6 \mathrm{~cm}$ olarak ölçülmüştür (Çizelge 3). Çevre şartları bitki boyunu önemli derece de etkilemekte ve aynı genotiplerin farklı yıl ve çevrede ölçülen bitki boyları arasında önemli farklıkların olduğu birçok araştırıcı tarafından bildirilmiştir (Sefaoğlu ve ark. 2009; Gül 2013, Albayrak 2014). Ürün yılların ortalamasına göre uzunlukları, 118.4 ile $128.4 \mathrm{~cm}$ arasında değişen TARSAN 10-18 ve ÇNR 12-13 en kısa bitki boyuna 
sahip olmuşlardır. Diğer taraftan en uzun bitki boyuna sahip çeşit/hatların ÇNR 12-12 $(141.1 \mathrm{~cm})$, ÇNR 11-12 $(140.6 \mathrm{~cm})$ ve Tunca $(139.1 \mathrm{~cm})$ olduğu belirlenmiştir. Genotiplerin farklı bitki boylarına sahip olması çeşit özelliği olmasına rağmen (Oral ve Kara 1989), ekolojik şartlara ve bakım uygulamalarına göre farklılık göstermektedir. Ayçiçeğinde dallanmayan sağlam gövdeli ve kısa boylu çeşitler makinalı hasat için önem arz etmektedir.

\section{Tabla çapı}

Varyans analiz sonuçları genotip etkinin tabla çapı üzerine etkisinin önemli $(p<0.01)$ olduğunu göstermiştir. Yılların birlikte analizinde tabla çapı üzerine yıl'ın etkisinin önemli $(p<0.01)$ olduğunu, genotip ve yıl $x$ genotip interaksiyonunun etkisinin ise önemsiz olduğunu ortaya koymuştur. Ürün yılların ortalamasına göre tabla çapları 18.5 ile 19.1 $\mathrm{cm}$ arasında değişen Tunca, 10-18, ÇNR 11-12 ve Pactol en büyük tabla çapına sahip olmuşlardır. Diğer taraftan en küçük tabla çapına sahip çeşit/hatların Tarsan 10-18 (17.4 cm), ÇNR 12-13 $(17.6 \mathrm{~cm})$ ve ÇNR10-24 $(17.8 \mathrm{~cm})$ olduğu tespit edilmiştir. Ayçiçeğinde tabla çapı başta çeşit özelliği olmasının yanı sıra sulama, toprak yapısı, yetiştirme teknikleri ve ekolojik koşullara bağlı olarak farklılık göstermektedir (Gürbüz ve ark. 2003). Nitekim araştırmamızda birinci ürün yılına ait ortalama tabla çapı $(18.7 \mathrm{~cm})$, ikinci ürün yılından $(17.7 \mathrm{~cm}) 1 \mathrm{~cm}$ daha küçük olmuş ve yıllar arasında görülen bu farklılık istatistiki olarak $p<0.01$ ihtimal seviyesinde önemli bulunmuştur. Tabla çapı ile ilgili yıllar arasında oluşan bu farklıı̆ı̆ iklim faktörlerinden kaynaklanmış olabileceği düşünülmektedir. Tabla çapı ile tabladaki tane sayısı arasında paralel bir ilişki olup tohum verimini doğrudan etkilemektedir. Nitekim araştırmamızda tabla çapı büyük olan genotiplerin yüksek verimliler arasında olduğu belirlenmiştir. Bu konuda yapılan birçok araştırmada tabla çapının tane verimi, bin tane ağırlığı ve yağ verimine olumlu etkisinin olduğu bildirilmiştir (Gençer 1986; Göksoy 1999; Kaya ve Atakişi 2003; Hladni ve ark. 2006). Tabla çapıyla ilgili yapılan çalışmalarda, Atakişi (1991)'nin 18-29 cm; Kara (1986)'nın 17.0-19.0 cm; Taşbölen (1988)'nin 16.3-19.5 cm; Göksoy (1999)'un 17.7$20.3 \mathrm{~cm}$ ve Karaaslan ve ark. 1999)'nin 17.2-19.8 cm: Sefaoğlu ve ark. (2009)'nın 19.6-21.6 cm; Albayrak (2014)'ın 19.0-19.4cm; Gül (2014)'ün $16.7-17.4 \mathrm{~cm}$ ve Karakuş ve ark. (2014) $17.7-20.2 \mathrm{~cm}$ arasında değişen değerleri bizim sonuçlarımızla benzerlik göstermektedir.

Çizelge 3. Farklı ayçiçeği genotiplerinin bitki boyu ve tabla çapı değerleri.

\begin{tabular}{|c|c|c|c|c|c|c|}
\hline \multirow{2}{*}{ Genotip } & \multicolumn{3}{|c|}{ Bitki boyu $(\mathrm{cm})$} & \multicolumn{3}{|c|}{ Tabla çapı (cm) } \\
\hline & 2013 & 2014 & 2013-2014 & 2013 & 2014 & 2013-2014 \\
\hline TUNCA & $150.3 \mathrm{a}$ & 127.9 & 139.1 & $19.8 \mathrm{ab}$ & 17.2 & 18.5 \\
\hline ÇNR 12-9 & $129.0 \mathrm{c}$ & 138.9 & 133.9 & $18.3 \mathrm{bd}$ & 17.9 & 18.2 \\
\hline ÇNR 11-12 & $150.5 \mathrm{a}$ & 130.6 & 140,6 & $20.5 \mathrm{a}$ & 16.5 & 18.5 \\
\hline ÇNR 12-3 & $126.8 \mathrm{c}$ & 133.9 & 130.3 & $16.7 \mathrm{~d}$ & 18.4 & 17.6 \\
\hline ÇNR 12-13 & $127,5 \mathrm{c}$ & 129.3 & 128.4 & $17.8 \mathrm{~cd}$ & 18.4 & 18.1 \\
\hline PACTOL & $135.3 \mathrm{bc}$ & 141.3 & 138,3 & $19.1 \mathrm{ac}$ & 19.1 & 19.1 \\
\hline ÇNR 10-24 & $145.0 \mathrm{ab}$ & 129.0 & 137.0 & $18.3 \mathrm{bd}$ & 17.3 & 17.8 \\
\hline TARSAN10-18 & $125.0 \mathrm{~cd}$ & 111.9 & 118.4 & $18.3 \mathrm{bd}$ & 16.5 & 17.4 \\
\hline DKF2525 & $114.8 d$ & 139.4 & 127.1 & $18.1 \mathrm{bd}$ & 17.6 & 17.9 \\
\hline ÇNR 12-12 & $146.1 \mathrm{ab}$ & 136.0 & 141.1 & $19.6 \mathrm{ac}$ & 18.5 & 19.0 \\
\hline Hat. & $* *$ & & & $*$ & & \\
\hline YIl & & & & & & $*$ \\
\hline \multicolumn{7}{|l|}{$\mathrm{Y}^{*} \mathrm{H}$} \\
\hline Ortalama & 135.0 & 132.6 & 133.4 & $18.7 \mathrm{a}$ & $17.7 \mathrm{~b}$ & 18.2 \\
\hline DK. (\%) & 5.6 & & & 6.9 & & 8.9 \\
\hline LSD (\%) & 11.5 & & & 1.9 & & 0.7 \\
\hline
\end{tabular}

*istatistiki olarak \%5'te önemli ( $\mathrm{P}<0.05)$; **istatistiki olarak \%1'de önemli $(\mathrm{P}<0.01)$

Farklı harflerle gösterilen ortalamalar arasındaki fark önemlidir.

\section{Bin tane ağırlığı}

Bin tane ağırlığı her iki ürün yılında çeşitlerden ve hatlardan önemli derecede etkilenmiştir. Birleştirilmiş analize ait varyans analiz sonuçları gerek genotip gerekse yıl $x$ genotip interaksiyonunun bin tane ağırlığı üzerine etkisinin istatistiksel olarak $p<0.05$ ihtimal sınırında önemli olduğunu göstermiştir (Tablo 4). Kalıtım derecesi oldukça yüksek olan bin tane ağırlığı verimi doğrudan etkilen faktörlerden biri olup, iklim ve toprak koşullarına bağlı olarak ekolojik faktörlerden önemli ölçüde etkilenmektedir. Nitekim birinci ürün yılında $63.7 \mathrm{~g}$ olan ortalama bin tane ağırlığı ikinci azda olsa bir artışla 65.7 g’a yükselmiştir. Benzer 
şekilde, aynı ekolojide bazı yağlık ayçiçeği çeşitlerinin farklı azot dozlarına tepkisini araştıran Gül (2013) araştırmanın birinci yılında çeşitlerin ortalaması olarak $66.3 \mathrm{~g}$ olan bin tane ağırlığını kurak ve sıcak geçen ikinci yılda $59.6 \mathrm{~g}$ olarak tespit etmiştir. íki yıllık ortalama sonuçlara göre, en yüksek bin tane ağırlığına (75.9 g) Pactol çeşidi sahip olmuş ve bu hattın bin tane ağırlığı diğer ve çeşit ve hatlardan yüksek olmuştur. Pactol çeşidini Tunca çeşidi takip etmiş ve bu çeşidin bin tane ağırlığı (71.4 g) Pactol çeşidi hariç diğer deneme materyalinden yüksek olmuştur. ÇNR 12-9 (68.9 g), ÇNR 11-12 (66.5 g) ve ÇNR 12-3 (65.1 g) hatlarının bin tane ağırlığı genel ortalamadan (64.8 g) yüksek olduğu belirlenmiştir. Yapılan farklı araştırmalarda (Çil ve ark., 2011; Evci ve ark., 2011; Sefaoğlu ve ark., 2009; Yıldız ve ark., 2009; Kara ve ark., 2013 ve Albayrak, 2014; Gül, 2013., Karakuş ve ark., 2014) bin tane ağırlıkları 38-83g arası çıkmıştır. Bu çalışmadan elde edilen değerler yazarların bildirdiği sonuçlarla benzerlik göstermektedir.

\section{Hektolitre ağırlığı}

Ayçiçeği genotiplerinin hektolitre ağırlıkları her iki ürün yılında farklılık göstermiştir ve bu farklılık $p<0.05$ ihtimal sınırında önemli bulunmuştur (Tablo 4). Yılların birlikte analizinde hektolitre ağırlığına genotip ve yıl'ın etkisi önemli $(p<0.05)$ olmuştur. Deneme de kullanılan genotiplerin ortalaması olarak ikinci ürün yılında genotiplerin hektolitre ağırlığı $\left(37.8 \mathrm{~kg} \mathrm{da}^{-1}\right)$, birinci ürün yılına (38.6 kg da-1) nazaran daha düşük olmuştur. Yıllar arasındaki bu farklılı̆ı̆ iklim ve çevre faktörlerinden kaynaklanmış olabileceği düşünülmektedir. Ürün yılların ortalamasına göre hektolitre ağırlıkları en düşük $30.9 \mathrm{~kg} \mathrm{da}^{-1}$ ile ÇNR 1212 ve $35.2 \mathrm{~kg}$ ile ÇNR 11-12 hattında tespit edilmişken en yüksek hektolitre ağırlığı $42.7 \mathrm{~kg} \mathrm{da}^{-1}$ ile Pactol ve $40.9 \mathrm{~kg} \mathrm{da}^{-1}$ ile TARSAN 10-18 çeşitlerinden elde edilmiştir. Farklı olgunlaşma süresine sahip ayçiçeği genotipleri arasında hektolitre ağırlığı bakımından meydana gelen bu farklılık genetik yapıdan kaynaklanmış olabilir.

Çizelge 4. Farklı ayçiçeği genotiplerinin bin tane ve hektolitre ağırlığı değerleri.

\begin{tabular}{|c|c|c|c|c|c|c|}
\hline \multirow{2}{*}{ Genotip } & \multicolumn{3}{|c|}{ Bin tane ağırlığı (g) } & \multicolumn{3}{|c|}{ Hektolitre ağırlığı (kg) } \\
\hline & 2013 & 2014 & 2013-2014 & 2013 & 2014 & 2013-2014 \\
\hline TUNCA & $73.8 \mathrm{a}$ & $68.9 c$ & $71.4 a b$ & $37.2 \mathrm{bd}$ & $38.6 \mathrm{c}$ & $37.9 \mathrm{~cd}$ \\
\hline ÇNR 12-9 & $68.1 \mathrm{ab}$ & $69.7 c$ & 68.9 bc & 36.0 de & $37.0 \mathrm{e}$ & $36.5 \mathrm{de}$ \\
\hline ÇNR 11-12 & $67,6 a b$ & $65.5 \mathrm{de}$ & $66.5 \mathrm{~cd}$ & $34.3 \mathrm{e}$ & $36.0 \mathrm{f}$ & $35.2 \mathrm{e}$ \\
\hline ÇNR 12-3 & $50.9 d$ & $73.3 b$ & $65.1 \mathrm{~cd}$ & $37.0 \mathrm{~cd}$ & $38.2 \mathrm{~cd}$ & $37.6 \mathrm{~cd}$ \\
\hline ÇNR 12-13 & $50.9 d$ & $57.2 \mathrm{~g}$ & $54,00 \mathrm{f}$ & $37.5 \mathrm{bd}$ & $40.3 \mathrm{~b}$ & $38.9 \mathrm{c}$ \\
\hline PACTOL & $68,6 a b$ & $83.1 \mathrm{a}$ & 75,9 a & $43.4 \mathrm{a}$ & $42.1 \mathrm{a}$ & 42.7 a \\
\hline ÇNR 10-24 & $60.6 \mathrm{bc}$ & $63.4 \mathrm{f}$ & $61.9 \mathrm{de}$ & $36.1 \mathrm{de}$ & $37.7 \mathrm{de}$ & $36.9 d$ \\
\hline TARSAN10-18 & $69.5 a b$ & $45.9 \mathrm{~h}$ & 57.7 ef & $39.0 \mathrm{bc}$ & $42.8 \mathrm{a}$ & $40.9 \mathrm{~b}$ \\
\hline DKF2525 & $69.8 a b$ & $66.4 \mathrm{~d}$ & 68.1 bc & 39.7 b & 41.9 a & $40.8 \mathrm{~b}$ \\
\hline ÇNR 12-12 & $53.4 \mathrm{~cd}$ & 63.9 ef & 58.7 ef & $30.3 \mathrm{f}$ & $31.6 \mathrm{~g}$ & $30.9 \mathrm{f}$ \\
\hline Hat. & $* *$ & $* *$ & $* *$ & $* *$ & $* *$ & $* *$ \\
\hline Yll & & & & & & $* *$ \\
\hline $\mathrm{Y} * \mathrm{H}$ & & & $* *$ & & & \\
\hline Ortalama & 63.7 & 65.7 & 64.8 & $37.1 \mathrm{~b}$ & $38.6 \mathrm{a}$ & 37.8 \\
\hline DK (\%) & 10.3 & 2.1 & 7.4 & 4.7 & 1.5 & 3.6 \\
\hline LSD (\%) & 9.5 & 2.1 & 4.8 & 2.5 & 0.8 & 1.4 \\
\hline
\end{tabular}

*istatistiki olarak \%5'te önemli $(\mathrm{P}<0.05)$; **istatistiki olarak \%1'de önemli $(\mathrm{P}<0.01)$

Farklı harflerle gösterilen ortalamalar arasındaki fark önemlidir.

\section{Tane verimi}

Tane verimi araştırmanın her iki yılında çeşit ve hatlardan önemli derecede etkilenmiştir. Varyans analiz sonuçları da toplam verim üzerine yıl ve genotipin önemli etkide bulunduğunu göstermiştir. Birinci araştırma yılında ortalama $396.6 \mathrm{~kg} \mathrm{da}^{-1}$ olan tane verimi ikinci ürün yılında $314.3 \mathrm{~kg} \mathrm{da}^{-1}$ olarak belirlenmiş ve yıllar arasında önemli farklılık meydana gelmiştir (Çizelge 5). Bütün bitkilerde olduğu gibi ayçiçeğinde, tane verimi iklim faktörü başta olmak üzere, çevre faktörlerinden önemli ölçüde etkilenmektedir. Nitekim bu çalışmamızda da birinci deneme yılında tane veriminim ikinci deneme yılına göre daha fazla olması, ikinci deneme yılındaki yağışın fazla fakat düzensiz olmasından kaynaklanabilir (Çizelge 3). Özellikle çiçeklenme ya da toplam vejetatif gelişme periyodunda bitkinin su sıkıntısı çekmesi tohum veriminde önemli oranda azalmalara neden olmaktadır (Kadayıfçı ve Yıldırım 2000). Şahin (2015) sulanan ayçiçeğinde çeşitlerin genetik yapılarına 
bağlı olarak tohum verimi \%8.0-43.0 arasında arttığını bildirmiştir.

Erzurum/Pasinler ekolojisinde yağlık ayçiçeği çeşit ve hatlarıyla yürütülen bu araştırmada, iki yıllık ortalama verimlere göre en yüksek tohum verimi Pactol (417.7 kg da ${ }^{-1}$ ) ve Tunca (400.6 kg da-1) çeşitlerinden elde edilmiştir. ÇNR $12-9(357.7 \mathrm{~kg} \mathrm{da}$ $\left.{ }^{1}\right)$ ve ÇNR 10-24 (375.4 kg da-1) hatlarının verimi ise diğer hatlardan önemli seviyede yüksek olmuştur. Farklı genotiplerle benzer ve değişik ekolojilerde yapılan çalışmalarda dekara tane verimi $131-500 \mathrm{~kg}$ $\mathrm{da}^{-1}$ arasında bulunmuştur. (Oral ve Kara, 1989; Kara, 1991; Tozlu ve ark., 2008; Sefaoğlu ve ark., 2009; Acar ve ark, 2011; Çil ve ark., 2011a; Çil ve ark., 2011; Evci ve ark., 2011; Kyrychenko ve Kolomatska, 2011; Albayrak, 2014; Karakuş ve ark., 2014). Genotiplerin tane veriminin değişkenliği, ekolojik şartlar, ekim zamanları, bakım, kültürel işlemler ve genetik farklılıklardan oluştuğu düşünülmektedir.

Çizelge 5. Farklı ayçiçeği genotiplerinin tane verimi, yağ oranı ve yağ verim değerleri.

\begin{tabular}{|c|c|c|c|c|c|c|c|c|c|}
\hline \multirow[b]{2}{*}{ Genotip } & \multicolumn{3}{|c|}{ Tane verimi (kg/da) } & \multicolumn{3}{|c|}{ Yağ oranı (\%) } & \multicolumn{3}{|c|}{ Yağ verimi (kg/da) } \\
\hline & 2013 & 2014 & 2013-2014 & 2013 & 2014 & $\begin{array}{l}2013- \\
2014\end{array}$ & 2013 & 2014 & 2013-2014 \\
\hline TUNCA & $492.4 \mathrm{a}$ & $308.7 a b$ & $400.6 \mathrm{ab}$ & 42 & 44 & 43 & 206.8 a & $119.3 \mathrm{c}$ & $163.1 \mathrm{ab}$ \\
\hline ÇNR 12-9 & $382.5 \mathrm{~cd}$ & $332.9 a b$ & 357.7 bd & 44 & 41 & 43 & $\begin{array}{c}168.3 \\
b d\end{array}$ & $123.2 \mathrm{bc}$ & 145.8 bc \\
\hline ÇNR 11-12 & $334.2 \mathrm{~d}$ & $235.4 \mathrm{c}$ & $284.8 \mathrm{e}$ & 33 & 35 & 34 & $110.3 \mathrm{f}$ & $84.9 \mathrm{~d}$ & $97.6 \mathrm{e}$ \\
\hline ÇNR 12-3 & $347.2 \mathrm{~cd}$ & $319.4 a b$ & $333.3 \mathrm{ce}$ & 43 & 35 & 39 & $149.3 \mathrm{de}$ & $122.3 \mathrm{bc}$ & $135.8 \mathrm{~cd}$ \\
\hline ÇNR 12-13 & $360.4 \mathrm{~cd}$ & $309.5 a b$ & $334.9 \mathrm{~cd}$ & 35 & 38 & 37 & $126.1 \mathrm{ef}$ & 124.6 bc & $125.4 \mathrm{~d}$ \\
\hline PACTOL & $461.6 \mathrm{ab}$ & 373.8 a & $417.7 \mathrm{a}$ & 39 & 38 & 39 & $180.0 \mathrm{ac}$ & $157.2 \mathrm{a}$ & $168.6 \mathrm{a}$ \\
\hline ÇNR 10-24 & $416.7 \mathrm{bc}$ & $334.1 \mathrm{ab}$ & $375.4 \mathrm{ac}$ & 44 & 40 & 42 & $183.3 \mathrm{ab}$ & 125.9 bc & $154.6 \mathrm{ac}$ \\
\hline TARSAN10-18 & $415.9 \mathrm{bc}$ & $304.4 \mathrm{ac}$ & $360.1 \mathrm{bd}$ & 37 & 36 & 37 & $153.8 \mathrm{~cd}$ & $130.3 \mathrm{ac}$ & $142.1 \mathrm{~cd}$ \\
\hline DKF2525 & $401.3 \mathrm{bd}$ & 350.8 a & $376.1 \mathrm{ac}$ & 47 & 36 & 42 & $188.6 \mathrm{ab}$ & $147.1 \mathrm{ab}$ & $167.9 \mathrm{a}$ \\
\hline ÇNR 12-12 & $354.2 \mathrm{~cd}$ & $273.8 \mathrm{bc}$ & 313.9 de & 35 & 34 & 35 & $123.9 \mathrm{f}$ & $86.2 \mathrm{~d}$ & $105.1 \mathrm{e}$ \\
\hline Hat. & $* *$ & $*$ & $* *$ & & & & $* *$ & $* *$ & $* *$ \\
\hline Yıl & & & $* *$ & & & & & & $* *$ \\
\hline $\mathrm{Y}^{*} \mathrm{H}$ & & & & & & & & & $* *$ \\
\hline Ortalama & 396.6 a & $314.3 \mathrm{~b}$ & 355.5 & 39,9 & 37.7 & 39.1 & $159.0 \mathrm{a}$ & $122.1 \mathrm{~b}$ & 140.6 \\
\hline DK. (\%) & 13.6 & 15.8 & 14.0 & & & & 12.4 & 15.6 & 13.7 \\
\hline LSD (\%) & 72.7 & 72.2 & $\begin{array}{c}(\mathrm{Y}): 8.6 \\
(\mathrm{H}): 49.9\end{array}$ & & & & 28.57 & 27.7 & 19.49 \\
\hline
\end{tabular}

*istatistiki olarak \%5'te önemli $(\mathrm{P}<0.05)$; **istatistiki olarak \%1'de önemli $(\mathrm{P}<0.01)$

Farklı harflerle gösterilen ortalamalar arasındaki fark önemlidir.

\section{Yağ oranı}

Erzurum/ Pasinler ekolojik koşullarında yağlık ayçiçeği genotipleri ile yürütülen bu çalışmada elde genotiplerin ortalama yağ oranı araştırmanın birinci yılında (\% 39.9), ikinci yılından (\% 37.7) \%2.2 oranında daha yüksek olmuştur. Ayçiçeği çevre şartlarına karşı dayanıklı olmasına rağmen iklim faktörleri (sıcaklık ve yağış gibi) verim ve verim ögeleri bakımından oldukça önemlidir. Araştırmacıların yapmış olduğu çalışmalarda; çevresel faktörlerin yağ kalitesini etkileyen önemli bir faktör olduğunu bildirmişlerdir (Zürrer and Bachofen 1985; Roche et al. 2004; Karaaslan vd 2007). Yağışın yetersiz olduğu dönemlerde tanelerdeki aşırı su kaybı kabuk oranının artmasına ve yağ oranının düşmesine neden olmaktadır (Kaya vd 2009).

Yapılan varyans analiz sonucunda iki yıllık ortalamalara göre, ÇNR 12-9 (\%43) ve ÇNR 10-24 (\%42) hatlarına ait yağ oranı Tunca (\%43) hariç, diğer çeşit ve hatlardan önemli ölçüde yüksek olduğu belirlenmiştir. Diğer taraftan ÇNR 11-12, TTAE 12-3, , ÇNR 12-13 ve Pactol genotiplerinin yağ oranları \%34- 39 arasında değişim göstermiştir. Yağ oranı bakımından ayçiçeği genotiplerinin birbirlerine göre farklılık oluşturması genotiplerin genetik yapılarının farklı olmasından kaynaklanmaktadır (Kılı 1997). Benzer ve aynı ekolojilerde farklı araştırmalarda yağ oranları (\%3154) arasında bulunmuştur (Oral ve Kara, 1989; Kara, 1991; Tozlu ve ark., 2008; Sefaoğlu ve ark., 2009; Acar ve ark, 2011;Çil ve ark., 2011a; Çil ve ark., 2011; Evci ve ark., 2011; Kyrychenko ve Kolomatska, 2011; Albayrak, 2014; Karakuş ve ark, 2014).

\section{Yağ verimi}

Tablo 5 'in incelenmesinden anlaşılacağı gibi, yağ verimi çalışmanın her iki yılında da genotiplerden etkilenmiştir $(p<0.05)$. Yapılan birleştirilmiş analizde genotip, yıl ve yıl $x$ genotip 
interaksiyonunun yağ verimi üzerinde $p<0.05$ ihtimal seviyesinde önemli olduğunu göstermiştir. Çeşit ve hatların ortalaması olarak birinci üretim yılında $159.0 \mathrm{~kg} \mathrm{da}^{-1}$ olan yağ verimi, ikinci ürün yılında $122.1 \mathrm{~kg} \mathrm{da}^{-1}$ olarak belirlenmiştir. Birinci deneme yılında yağ veriminin ikinci deneme yılına göre fazla olması bu yıldaki tane (396.6 kg da-1) ve yağ oranın (\%39.9) ikinci yıla (314.3 kg da-1 $\mathrm{kg}^{-10}$ \%37.7) göre fazla olmasından kaynaklanabilir (Çizelge 5).

iki yıllık ortalamalara göre kontrol çeşit olarak kullanılan Pactol (168.6 kg da-1), DKF 2525 (167.9 kg da-1) ve Tunca (163.1 kg da ${ }^{-1}$ ) çeşitlerinin yağ verimleri yüksek olmasına rağmen hariç ÇNR 129 (145.8 kg da-1) ve ÇNR 10-24 (154.6 kg da-1) hatlarına ait yağ verimleri değerleri diğer hatlardan önemli derecede yüksek olmuştur. Tane verimi ve yağ oranı bileşkesi olan yağ verimi, çeşit özelliği olarak ortaya çıktığı gibi, tane verimi ve yağ oranını etkileyen tüm faktörlerin de etkisi altında kalabilir. Farklı çeşit ve bölgelerde yapılan çalışmalarda yağ verimlerini Kara (1991) 82.2-110.5 kg da-1, Karadoğan ve Özgödek (1994) 43.0-69.8 kg da-1, Yılmaz ve Bayraktar (1996) 78.8-98.8 kg da-1, Tunçtürk vd (2005) $52.1 \mathrm{~kg} \mathrm{da}{ }^{-1}$, Doğan (2010) 10.70-32.28 kg da-1, Gül (2013) 120.4-132.0 kg da-1 olarak belirtmişler, bu araştırmacıların bildirmiş olduğu sonuçlar araştırmadan elde edilen değerlerden düşük bulunmuştur. Çalışmada elde edilen sonuçlar ile araştırmacıların elde ettiği sonuçlar arasında görülen bu farklılığın çeşit, çevre ve iklim şartlarından kaynaklanabileceği düşünülmektedir.

\section{Sonuç ve Öneriler}

Erzurum yöresinde daha yüksek performans gösterecek yağlık ayçiçeği çeşit ve çeşit adaylarının yetiştirme olanaklarını belirlemek amacıyla 20132014 yıllarında iki yıl süreyle yürütülen çalışma sonucunda, en yüksek tohum ve yağ verimi Pactol (417.7 kg da-1, $\left.168.6 \mathrm{~kg} \mathrm{da}^{-1}\right)$, en yüksek yağ oranı ise Tunca (\%43), çeşidinden elde edilmiştir. Araştırma sonucunda çiftçi açısından bakıldığında Pactol, sanayici açısından ise Tunca çeşidinin üretiminin yapılmasının uygun olduğu belirlenmiştir. Denemede kullanılan hatlar içerisinde ise incelenen veriler dikkate alınarak bir değerlendirme yapıldığında, verim ve verim unsurları bakımından ÇNR 12-9 ve ÇNR 10-24 hatlarının ön plana çıktığını ve bu hatlar ile çalışmaya devam edilmesinin uygun olacağı kanaatine varılmıştır.

\section{Kaynaklar}

Acar, M., Gizlenci, Ş., Öner, E.K. 2011. Sunflower breeding studies in Black Sea Area. Sunflower breeding and adaptation studies in Cukurova Region. International
Symposium on Sunflower Genetic Resources. October 16-20, 2011. s.47. Kuşadası, İzmir, Turkey.

Albayrak, Ş.N. 2014. Ekim Zamanlarına Göre Uygulanan Değişik Azotlu Gübre Formlarının Yağlık Ayçiçeği (Helianthus annuus L.) Çeşitlerinin Verim ve Verim Unsurlarına Etkisi. Atatürk Üniversitesi Fen Bilimleri Enstitüsü. Yüksek Lisans Tezi.

Anonim, 2015. 2014 Yılı Ayçiçeği Raporu. Kooperatifçilik Genel Müdürlüğü, s.4. Anonim, 2016 koop.gtb.gov.tr/data/.../2016\%20Ayçiçeği\% 20Raporu\%20son\%20hali.pdf (Erişim tarihi: 04.11.2017).

Atakişi, i..K. 1991. Yağ. Tekirdağ bitkileri yetiştirme ve ıslahı, Trakya Üniversitesi Ziraat Fakültesi Yayınları No: 148, $181 \mathrm{~s}$.

Carter, F.C. 1978. Sunflower Science and Technology. American Society of Agronomy, 505 p, Wisconsin, USA.

Çil, A., Çil, A.N., Evci, G., Kıllı, F. 2011. Bazı yağlık ayçiçeği (Helianthus annuus L.) hibridlerinin Çukurova koşullarında bitkisel ve tarımsal özelliklerinin belirlenmesi. "Türkiye IX. Tarla Bitkileri Kongresi" 12-15 Eylül 2011.S.84. Bursa.

Çil, A.N., Çil, A., Evci, G., Kaya, Y. 2011a. Sunflower breeding and adaptation studies in Çukurova region. International symposium on sunflower genetic resources. October 16-20, 2011. p.53. Kuşadası, İzmir, Turkey.

Doğan, M. 2010. Sulanmayan koşullarda ayçiçeği (Helianthus annuus L.) çeşitlerinin tarımsal ve teknolojik özelliklerinin belirlenmesi üzerine bir araştırma. Yüksek Lisans Tezi, Çukurova Üniversitesi Fen Bilimleri Enstitüsü, Adana.

Ekin, Z. 2005. Van'da Yağlık Ayçiçeği (Helianthus annuus L.) Çeşitlerinde farklı ekim zamanı ve bitki sıklıklarının tarımsal, fizyolojik, verim ve kalite özellikleri üzerine etkileri. Yüzüncü Yıl Üniversitesi Fen Bilimleri Enstitüsü Tarla Bitkileri Anabilim Dalı Doktora Tezi.

Evci, G., Pekcan, V., Yılmaz, I..M., Kaya, Y., Şahin, i., Citak, N., Tuna, N., Ay, O., Pilaslı, A. 2011. Ayçiçeğinde (Helianthus annuus L.) yağ kalitesi ve verim öğeleri arasındaki ilişkilerin belirlenmesi. Türkiye IX. Tarla Bitkileri Kongresi. s.279. Bursa.

Gençer, O. 1986. Ayçiçeğinde verim Ve Unsurlarını Korelasyon ve Path Katsayısı Analiz Üzerinde Bir Araştırma. TUBiTAK Yayın No: 629, Ankara.

Goyne, P.J., Hammer, G.L. 1982. Phenology of sunflower cultivars. $2^{\text {nd }}$ controlled environment studies of temperature and 
photoperiod effects. Australian Journal of Agricultural Research, 33(2): 251-261.

Göksoy, A.T. 1999. Kendilenmiş ayçiçeği (Helianthus annuus L.) hatlarından geliştirilen sentetik çeşitlerin bazı tarımsal özellikleri üzerinde bir araştırma. Tr. Journal of Agricultural and Forest, 23(2): 349-354.

Gül, V. 2014. Farklı Gelişme Sürelerine Sahip Yağıık Ayçiçeği Geenotiplerin Farklı Azot Dozlarına Tepkileri. Atatürk Üniversitesi Fen Bilimleri Enstitüsü. Doktora Tezi.

Gürbüz, B., Kaya, M. D., Demirtola, A. 2003. Ayçiçeği tarımı. Hasat Yayıncılık Ltd. Şti. ISBN- 9758377-23-X. Ege Basım.

Hladni, N., Skoric, D., Balalic, M.K., Ivanovic, M., Sakac, Z., Jovanovic, D. 2006. Combining ability for oil content and its correlations with other yield components in sunflower (Helianthus annuus L.). Helia 29(44): 101110.

Kacar, B. 2009. Toprak Analizleri (ikinci Baskı). Nobel Yayın No: 1387, Ankara.

Kadayıfçı, A., Yıldırım, O. 2000. Ayçiçeğinin su-verim ilişkileri. Turkey Journal Agricultural and Forest, 24: 137-145.

Karaaslan, D., Söğüt, T., Şakar, D., 1999. Diyarbakır sulu koşullarında ikinci ürün tarımına uygun ayçiçeği çeşitlerinin belirlenmesi. Türkiye III. Tarla Bitkileri Kongresi, 15-18 Kasım, Adana, 52-56.

Karaaslan, D., Tonçer, Ö., Söğüt, T. 2007. Güneydoğu Anadolu Bölgesi koşullarında bazı ayçiçeği (Helianthus annuus I.) çeşitlerinin verim ve bazı verim özellikleri bakımından değerlendirilmesi. Harran Üniversitesi Ziraat Fakültesi Dergisi, 11(1/2): 31-38.

Kara, K. 1986. Erzurum ekolojik koşullarında bazı yağlık ayçiçeği (Helianthus annuus L.) çeşitlerinin fenolojik, morfolojik özellikleriyle verim ve verim öğeleri üzerinde bir araştırma. Doğa Türk Tarım ve Ormancılık Dergisi, 1: 366-377.

Kara, K. 1991. Bazı yerli ve yabancı yağlık ayçiçeği (Helianthus annuus L.) çeşitlerinin zirai karakterleri üzerine bir araştırma. Atatürk Üniversitesi Ziraat Fakültesi Dergisi 22(2): 6277. Erzurum.

Kara, K., Öztürk, E., Polat, T. 2013. Farklı yetişme sürelerine sahip yağlık ayçiçeği çeşitlerinin kuru ve sulu koşullarda kışlık (dondurma) ve yazlık olarak yetiştirilmesi üzerine bir araştırma. Türkiye 10.Tarla Bitkileri Kongresi, 10-13 Eylül, Konya.

Karakuş, A., Kaya, C., Sefaoğlu, F. 2014. Bazı yağlık ayçiçeği (Helianthus annuus L.) çeşit adayı ve çeşitlerinin erzurum koşullarında adaptasyon kabiliyetlerinin belirlenmesi. Enerji Tarımı ve Biyoyakıtlar 4. Ulusal Çalıştayı. 28-29 Mayıs 2014 Samsun. 115122.

Karadoğan, T., Özgödek, Z. 1994. Çerezlik karakterdeki bazı ayçiçeği ekotiplerinin verim ve verim unsurları üzerine bir araştırma. Atatürk Üniversitesi Ziraat Fakültesi Dergisi, 25(2): 188-201.

Kaya, Y., Atakisi, I.K. 2003. Path and correlation analysis in different yield characters in sunflower (Helianthus annuus L.). Anadolu Journal 13: 31-45.

Kaya, Y., Evci, G., Pekcan, V., Gücer, T., Yılmaz, M.í. 2009. Açiçeğinde yağ verimi ve bazı verim öğeleri arasında ilişkilerin belirlenmesi. Ankara Üniversitesi Ziraat Fakültesi Tarım Bilimleri Dergisi, 15(4): 310-318.

Kıllı. F. 1997. Kahramanmaraş ekolojik koşullarında yağlık melez ayçiçeği (Helianthus annus L.) çeşitlerinin verim ve verim unsurları üzerine bir araştırma. Doğa Turkish Journal of Agriculture and Forestry, 21: 149-155.

Kurt, O. 2002. Tarla Bitkileri Yetiştirme Tekniği. OMÜ, Ziraat Fakültesi Ders Kitabı No: 44.

Kyrychenko, V.V., Kolomatska, V.P. 2011. Results of the scientific program for sunflower breeding; sunflower breeding and adaptation studies in Cukurova region. International Symposium on Sunflower Genetic Resources. October 16-20, 2011, s.26. Kuşadası, İzmir, Turkey.

Oral, E., Kara, K. 1989. Erzurum ekolojik koşullarında bazı yağlık ayçiçeği (Helianthus annuus L.) çeşitleri üzerinde bir araştırma. Doğa Türk Tarım ve Ormancılık Dergisi. 13: 342-355.

Roche, J., Essahat, A., Bouniols, M., El-Asri, Z., Mouloungui, M., Mondies, Alghoum, M. 2004. Diversified composition of sunflower (Helianthus annuus L.). Journal of EcoPhysiology, 3: 59-71.

Sefaoğlu, F., Özer, H., Öztürk, E., Polat, T. 2009. Erzurum ekolojik koşullarında bazı yağlık ayçiçeği çeşitlerinin adaptasyonu ve önemli tarımsal özelliklerinin belirlenmesi. Türkiye VIII. Tarla Bitkileri Kongresi. 19-22 Ekim 2009, Hatay/Türkiye.

Şahin, T. 2015. Tokat-Erbaa Şartlarında Bazı Ayçiçeği (Helianthus annuus L.) çeşitlerinin Performanslarının Belirlenmesi. Yüksek Lisans Tezi GOÜ Fen Bilimleri Enstitüsü Tarla Bitkileri Anabilim Dalı, Tokat.

Taşbölen, M., 1988. Ayçiçeği Çeşitlerinin Verim ve Verim Unsurları Üzerine Etkisi. Yüksek Lisans Tezi (Yayınlanmamış), Trakya Üniversitesi Fen Bilimleri Enstitüsü Tarla Bitkileri Ana Bilim Dalı, Tekirdağ. 
Tozlu, E., Dizikısa, T., Kumlay, A.M., Okçu, M., Pehluvan, M., Kaya, C. 2008. ErzurumPasinler ekolojik koşullarında yetiştirilen bazı yağlık ayçiçeği (Helianthus annuus L.) hibridlerinin agronomik performanslarının belirlenmesi. Ankara Üniversitesi, Ziraat Fakültesi, Tarım Bilimleri Dergisi, 14(4): 359364.

Tunçtürk, M., Eryiğit, T., Yılmaz, İ. 2005. Van-Erciş koşullarında bazı ayçiçeği (Helianthus annuus L.) çeşitlerinin verim ve verim ögelerinin belirlenmesi üzerine bir araştırma. Türkiye VI. Tarla Bitkileri Kongresi, 5-9 Eylül 2005, Antalya.

Yıldız, G., Özer, H., Polat, T., Öztürk, E., Sefaoğlu, F. 2009. Farklı ekim zamanlarının yağlık ayçiçeğinin verim ve tarımsal özellikleri üzerine etkisi. Türkiye VIII. Tarla Bitkileri Kongresi. 19-22 Ekim 2009, Hatay/Türkiye.

Yılmaz, H.A., Bayraktar, N. 1996. iki farklı lokasyonda 12 ayçiçeği (Helianthus annuus L.) çeşidinin verim ve verim unsurlarının belirlenmesi. Tarım Bilimleri Dergisi, 2(3): 6369.

Zürrer, H., Bachofen, R. 1985. Yields of tree cultivars of sunflower in Switzerland. Biomass, 7: 297302. 